\title{
KEANEKARAGAMAN GASTROPODA PADA ZONA INTERTIDAL TENGAH (MIDLE INTERTIDAL ZONE) DAN ZONA INTERTIDAL BAWAH (LOWER INTERTIDAL ZONE) DAERAH PADANG LAMUN DESA WAAI
}

\author{
Sriyanti. I. A. Salmanu \\ Staf Pengajar Program Studi Pendidikan Biologi \\ E-mail: salmanubio@yahoo.co.id
}

\begin{abstract}
Background: Seagrass grows and spreads in nearly all parts of the intertidal zone. Waai village has characteristic sloping coastal water and have different patterns of zonation of seagrass in the intertidal zone's third-impact on the presence of seagrass and the organisms in it.

Methods: The study was conducted in coastal waters Waai village, in the middle of the intertidal zone (middle intertidal zone) and the lower intertidal zone (lower zone intertidal). The samples in this study are all kinds of gastropods found in each plot observation station of 100 plots. Gastropod species diversity using diversity index formula Shannon - Wiener referred to under Ludwig and Reynolds.

Results: From the results of the study found 8 species of gastropods and has a diversity index that is currently in the middle intertidal zone, the average diversity index of 1.76, while in the lower intertidal zone, the average gastropod diversity index was 1.45.

Conclusion: diversity index indicates the middle intertidal zone, the average diversity index of 1.76 , while in the lower intertidal zone, the average index of diversity of gastropods is 1.45 , this is caused by the different seagrass zonation patterns and habits of the people who frequently uses seagrass area for commercial purposes.
\end{abstract}

Keywords: Diversity of Gastropoda, Intertidal Zone

\begin{abstract}
Abstrak
Latar Belakang: Lamun tumbuh dan menyebar hampir pada semua bagian di zona intertidal. Desa Waai memiliki karakteristik perairan pantai yang landai dan memiliki pola zonasi lamun yang berbeda pada ketiga zona intertidal yang berdampak pada keberadaan lamun dan organisme yang ada di dalamnya.

Metode: Penelitian ini dilakukan di perairan pantai desa Waai, pada zona intertidal tengah (middle intertidal zone) dan zona intertidal bawah (lower intretidal zone). Sampel dalam penelitian ini adalah seluruh jenis gastropoda yang terdapat pada masing-masing plot stasiun pengamatan yaitu 100 plot. Keanekaragaman spesies gastropoda menggunakan rumus indeks keaneka-ragaman Shannon Wiener yang diacu dalam Ludwig and Reynolds.

Hasil: Dari hasil penelitian ditemukan 8 jenis gastropoda dan memiliki indeks keanekaragaman sedang yaitu pada middle intertidal zone, rata-rata indeks keanekaragaman sebesar 1,76 sedangkan pada lower intertidal zone, rata-rata indek keanekaragaman gastropoda adalah 1,45.

Kesimpulan: Indeks keanekaragaman menunjukkan pada middle intertidal zone, rata-rata indeks keanekaragaman sebesar 1,76, sedangkan pada lower intertidal zone, rata-rata indek keanekaragaman gastropoda adalah 1,45, hal ini disebabkan oleh pola zonasi lamun yang berbeda dan kebiasaan masyarakat yang sering menggunakan daerah padang lamun untuk kepentingan komersil.
\end{abstract}

Kata Kunci: Keanekaragaman Gastropoda, Zona Intertidal 


\section{PENDAHULUAN}

Padang lamun merupakan salah satu ekosistim khas yang ada pada zona intertidal. Lamun tumbuh dan menyebar hampir pada semua bagian di zona intertidal. Zona intertidal sendiri adalah zona antara zona supralitoral dan zona infralitoral. Campbell dalam Leiwakabessy (1999), membagi zona intertidal atas tiga zona yaitu; 1) zona intertidal atas (upper intertidal zone), 2) zona intertidal tengah (middle intertidal zone), dan 3) zona intertidal bawah (lower intertidal zone). Ketiga zona intertidal ini memiliki karakteristik lingkungan yang berbeda-beda. Penyebaran tumbuhan lamun pada ketiga zona intertidal ini pun berbeda-beda. Dengan memperhatikan peran padang lamun bagi gastropoda, maka diduga penyebarannya pun selalu mengikuti penyebaran padang lamun pada perairan pantai (zona intertidal). Salah satu daerah yang memiliki padang lamun di pulau Ambon adalah desa Waai.

Desa Waai merupakan salah satu dari sekian banyak desa di pulau Ambon yang memiliki keunikan dengan hadirnya padang lamun pada perairan pantainya. Desa ini memiliki karakteristik perairan pantai yang landai dan memiliki pola zonasi lamun yang berbeda pada ketiga zona intertidal yang berdampak pada keberadaan lamun dan organisme yang ada di dalamnya. Pada zona intertidal atas (upper intertidal zone) kondisinya tidak memadai untuk kehidupan tumbuhan lamun, karena ketika keadaan pantai surut daerah ini tidak terendam air sehingga keberaadan hewan lain di daerah ini ketika keadaan surut sulit ditemukan. Zona yang dapat ditemukan tumbuhan lamun adalah zona intertidal tengah (middle intertidal zone), dan zona intertidal bawah (lower intertidal zone), keberadaan organisme lain pada kedua zona ini juga mudah ditemukan.

\section{METODE}

Penelitian ini dilakukan di perairan pantai desa Waai, pada zona intertidal tengah (middle intertidal zone) dan zona intertidal bawah (lower intretidal zone). Sampel dalam penelitian ini adalah seluruh jenis gastropoda yang terdapat pada masing-masing plot stasiun pengamatan yaitu 100 plot.

Keanekaragaman spesies gastropoda menggunakan rumus indeks keanekaragaman Shannon-Wiener yang diacu dalam Ludwig and Reynolds dalam Leiwakabessy (1999).

\section{HASIL DAN PEMBAHASAN \\ Hasil \\ Gastropoda yang ditemukan di lokasi penelitian}

Berdasarkan hasil pengamatan, ditemukan jenis-jenis gastropoda yang datanya dapat dilihat pada gambar di bawah ini. (a)

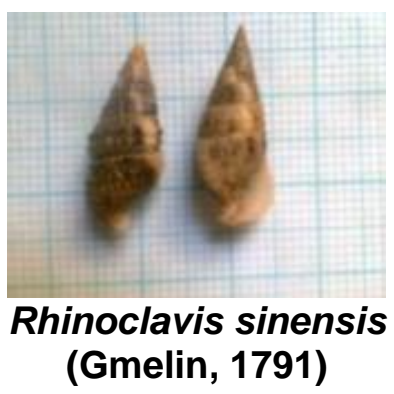

(d) (b)

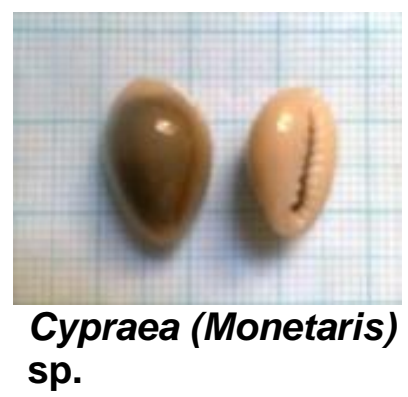

(e) (c)

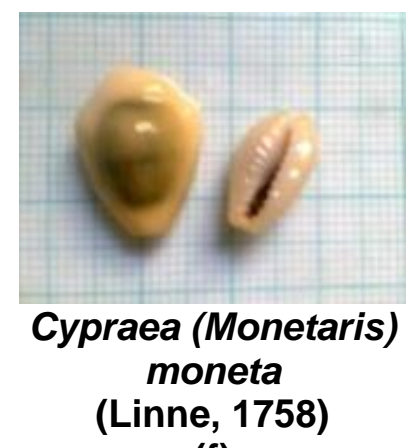

(f) 


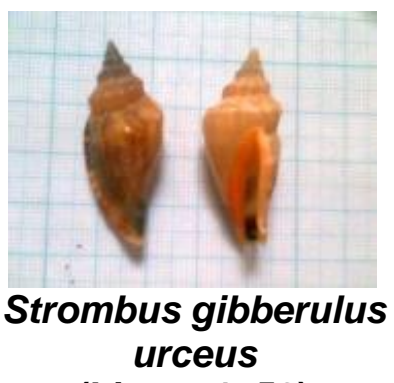

(Linne, 1758)

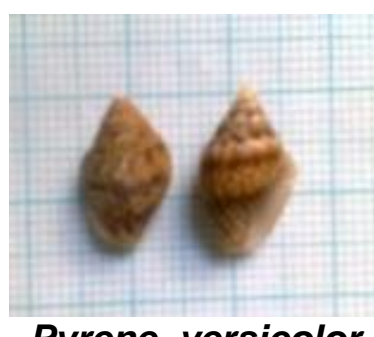

Pyrene versicolor (Sowerby, 1832)

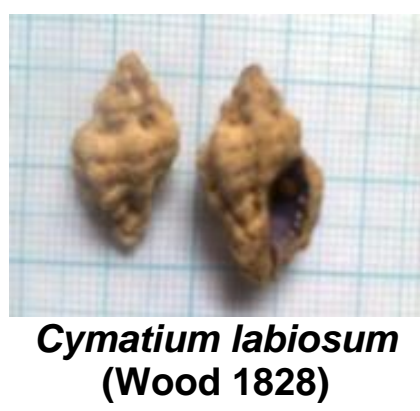

(i)

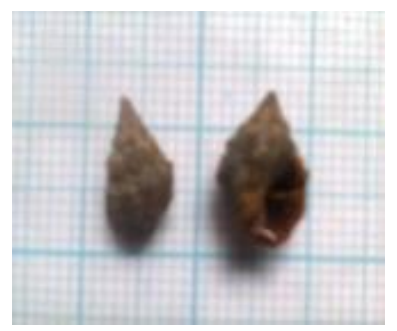

Nassarius cf. echinatus

(A. Adams, 1852 )

Nassarius pullus (Linne, 1758)

lokasi penelitian dapat dilihat pada Tabel $1 \mathrm{di}$ bawah ini.

Tabel 1. Komposisi Taksa Gastropoda yang Ditemukan pada Lokasi Penelitian Desa Suli dan Desa Waai.

\begin{tabular}{|c|c|c|c|}
\hline Ordo & Family & Genus & Spesies \\
\hline \multirow[t]{3}{*}{ Mesogastropoda } & Potamididae & $\begin{array}{l}\text { Rhinoclavi } \\
s\end{array}$ & Rhinoclavis sinensis, Gmelin, 1791 \\
\hline & Cypraeaidae & Cypraea & $\begin{array}{l}\text { Cypraea (Monetaris) sp } \\
\text { Cypraea (Monetaris) moneta, Linne } 1758\end{array}$ \\
\hline & Strombidae & Strombus & Strombus gibberulus urceus (Linne, 1758) \\
\hline \multirow[t]{2}{*}{ Neogastropoda } & Pyrenida & Pyrene & Pyrene versicolor (Sowerby, 1832) \\
\hline & $\begin{array}{l}\text { Cymatlida } \\
\text { Nassaridae }\end{array}$ & $\begin{array}{l}\text { Cymatilum } \\
\text { Nassarius }\end{array}$ & $\begin{array}{l}\text { Nassarius (Plicarcularia) pullus L. } 1758 \\
\text { Nassarius cf. echinatus (A. Adams, } 1852 \text { ) }\end{array}$ \\
\hline
\end{tabular}

Tabel 1 di atas menunjukkan jenis-jenis gastrpoda yang ditemukan pada lokasi penelitian yaitu 8 jenis gastropoda terdiri dari 2 ordo, 6 famili dan 6 genus. Sesuai dengan hasil penelitian ternyata terdapat 8 jenis gastropoda pada daerah padang lamun perairan pantai desa Suli. Genus Nasarius dan Cyprae ditemukan 2 jenis dan keempat genus yang lain yaitu Rhinoclavis, Pyrene, Conus dan Cymatiium masing-masing genus hanya ditemukan 1 jenis.

\section{Keanekaragaman Gastropoda}

Perhitungan indeks keanekaragaman dilakukan dengan menggunakan rumus Indeks Shannon - Wienner. Hasil perhitungan indeks keanekaragaman selengkapnya dapat dilihat pada, sedangkan ringkasannya disajikan pada Tabel 2 di bawah ini. 
Tabel 2. Keanekaragaman Gastropoda Pada Zona Intertidal Desa Waai

\begin{tabular}{|c|c|c|c|}
\hline \multirow{2}{*}{ No. } & \multirow{2}{*}{ Transek } & \multicolumn{2}{|c|}{ Zona } \\
\hline & & Midlle & Low \\
\hline 1. & 1 & 1.90 & 1.74 \\
\hline 2. & 2 & 1.92 & 1.67 \\
\hline 3. & 3 & 1.86 & 1.47 \\
\hline 4. & 4 & 1.82 & 1.32 \\
\hline 5. & 5 & 1.46 & 1.53 \\
\hline 6. & 6 & 1.02 & 1.04 \\
\hline 7. & 7 & 1.62 & 1.12 \\
\hline 8. & 8 & 1.99 & 1.49 \\
\hline 9. & 9 & 2.03 & 1.35 \\
\hline 10. & 10 & 1.98 & 1.72 \\
\hline \multicolumn{2}{|c|}{ Rata-rata } & 1,76 & 1,45 \\
\hline
\end{tabular}

Tabel 2 di atas menunjukkan bahwa rata-rata indeks keanekaragaman menunjukkan pada middle intertidal zone, rata-rata indeks keanekaragaman sebesar 1,76, sedangkan pada lower intertidal zone, rata-rata indek keanekaragaman gastropoda adalah 1,45.

\section{Pembahasan}

\section{Gastropoda yang ditemukan di lokasi penelitian}

Gastropoda adalah salah satu kelompok makroinvertebrata yang paling banyak diketahui berasosiasi dengan lamun di Indonesia, dan mungkin yang paling banyak dieksploitasi. Sejumlah studi tentang gastropoda di daerah subtropik telah menunjukkan bahwa moluska merupakan komponen yang paling penting bagi ekosistem lamun, baik pada hubungannya dengan biomasa dan perannya pada aliran energi pada sistem lamun (Watson et al dalam Kiswara dan Winardi, 1999). Gastropoda utama pada padang lamun subtropis adalah detrivor dengan sangat sedikit yang langsung memakan lamun (Kikuchi dalam Aswandi 1999). Gastropoda cenderung memakan perifiton (Klumpp et al, dalam Aswandi dan Azkab, 2000).

Jenis-jenis gastrpoda yang ditemukan pada lokasi penelitian yaitu 8 jenis gastropoda terdiri dari 2 ordo, 6 famili dan 6 genus. Sesuai dengan hasil penelitian ternyata terdapat 8 jenis gastropoda pada daerah padang lamun perairan pantai desa Suli. GenusNasarius dan Cyprae ditemukan 2 jenis, dan keempat genus yang lain yaitu
Rhinoclavis, Pyrene, Conus dan Cymatiium masing-masing genus hanya ditemukan 1 jenis.

Suwondo, et al, (2006) mencatat 15 spesies moluska (11 gastropoda dan 4 bivalvia) dari padang lamun di Teluk Banten, Barat Daya Laut Jawa. Pada data yang ditulis oleh Suwondo et all., (2006) menunjukkan eksploitasi yang berlebihan terhadap sumberdaya lamun (e.g hanya 4 juvenil Trochus niloticus, dengan diameter 3$5 \mathrm{~mm}$ yang ditemukan) dan efek dari polusi (endapan) dari pada pola ekologi. Pada kajian yang sama yang dilakukan di Teluk Kotania, Seram Barat, Wouthuyzen dan Sapulette (1994) mencatat 24 spesies dari Pulau Osi, 6 spesies dari Desa Pelita Jaya dan 22 spesies dari Desa Kotania. Salmanu (2012) menemukan 13 spesies gastropoda di daerah padang lamun desa Suli.

Dari hasil penelitian di daerah padang lamun perairan pantai desa Waai ditemukan 8 jenis gastropoda, hal ini disebabkan oleh eksploitasi yang berlebihan dari masyarakat sekitar. Berdasarkan pengamatan dan wawancara terhadap penduduk sekitar terungkap bahwa telah terjadi penangkapan secara terus-menerus untuk kepentingan komersil, sehingga menurunkan kualitas jumlah dan jenis gastropoda.

\section{Keanekaragaman Gastropoda}

Indeks keanekaragaman menurut Fachrul (2007), merupakan parameter vegetasi yang sangat berguna untuk membandingkan berbagai komunitas, terutama untuk mempelajari pengaruh faktor-faktor lingkungan atau abiotik 
terhadap suatu komunitas atau untuk mengethui suksesi atau stabilitas komunitas. Soegyanto dalam Papilaya (2002) mengungkapkan bahwa suatu komunitas memiliki keanekaragaman yang tinggi jika komunitas itu disusun oleh banyak spesies. Sebaliknya jika komunitas itu disusun oleh sangat sedikit spesies, dan jika hanya sedikit saja yang dominan, maka keanekaragaman jenis rendah.

Indeks keanekaragaman pada lokasi penelitian menunjukkan middle intertidal zone, rata-rata indeks keanekaragaman sebesar 1,76, sedangkan pada lower intertidal zone, rata-rata indek keanekaragaman gastropoda adalah 1,45. Sesuai dengan indeks keanekaragaman jenis menurut Shannon-Wiener (Fachrul, 2007) yang menyatakan jika nilai $1<\mathrm{H}^{1}<3$ menunjukan bahwa keanekaragaman pada transek pengamatan adalah sedang melimpah. Suprapto dalam Leiwakabessy (1999), mengungkapkan bahwa apabila indeks keanekaragaman Shannon suatu komunitas mendekati angka 4, maka komunitas tersebut dikatakan beragam. Leksono (2007) juga mengungkapkan bahwa semakin banyak jumlah spesies dengan proporsi yang seimbang menunjukan keanekaragaman semakin tinggi. Maka indeks keanekaragaman gastropoda pada perairan pantai desa Waai adalah sedang.

Salah satu penyebab indeks keanekaragaman gastropoda sedang pada daerah padang lamun perairan desa Waai, berdasarkan pengamatan dan wawancara terhadap penduduk sekitar terungkap bahwa telah terjadi penangkapan secara terusmenerus untuk kepentingan komersil, sehingga menurunkan kualitas jumlah dan jenis gastropoda. Sedangkan nilai indeks keanekaragaman antara zona intertidal tengah (middle intertidal zone) yaitu 1,76 dan zona intertidal bawah (middle intertidal zone) yaitu 1,45 desa Suli yang tidak terlalu berbeda disebabkan karena pola zonasi padang lamun yang tidak terlalu berbeda antara kedua zona intertidal.

\section{KESIMPULAN}

Indeks keanekaragaman menunjukkan pada middle intertidal zone, rata-rata indeks keanekaragaman sebesar 1,76, sedangkan pada lower intertidal zone, rata-rata indek keanekaragaman gastropoda adalah 1,45, hal ini disebabkan oleh pola zonasi lamun yang berbeda dan kebiasaan masyarakat yang sering menggunakan daerah padang lamun untuk kepentingan komersil.

\section{DAFTAR PUSTAKA}

Aswandi dan Askap, 2000. Hubungan Fauna Dengan Padang lamun. Jakarta. Oseana, Vol. XXV, No 3.

Aswandi. 1999. Dinamika Fanua Krustasea Bentik di Padang Lamun Teluk Kuta Lombok. Jakarta. Dinamika Komunitas Biologis Pada Ekosistim Lamun di Pulau Lombok, Indonesis. Pusat Penelitian dan Pengembangan Oseanologi.

Fachrul. 2007. Metode Sampling Bioekologi. Jakarta. PT Bumi Aksara.

Kiswara dan Winardi. 1999. Sebaran Lamun di Teluk Kuta dan Teluk Gerubuk, Lombok. Jakarta. Dinamika Komunitas Biologis Pada Ekosistim Lamun di Pulau Lombok, Indonesis. Pusat Penelitian dan Pengembangan Oseanologi.

Leiwakabessy. 1999. Gastropoda di Perairan Pasang Surut Pantai Pulau Ambon Analisis Keanekaragaman dan Penyusunan Penuntun Praktikum Identifikasi Dikotomis Atas Dasar Cangkang. Tesis. Tidak diterbitkan. Malang. IKIP Malang.

Laksono. 2007. Ekologi. Pendekatan Deskriptif dan Kuantitatif. Malang. Bayumedia.

Papilaya. 2002. Keanekaragaman, Pola Sebaran dan Asosiasi Pohon di Hutan Daerah Tangkapan Air Dusun Kusukusu Sereh Urimesing Kota Ambon. Tesis. Tidak diterbitkan. Malang. Universitas Negeri Malang.

Romimohtarto dan Juana. 2000. Biologi Laut. IImu Pengetahuan Tentang Biota Laut. Jakarta. PT. Penertbi Djabatan. 